\title{
The Evolution of the Meaning of Chinese character "Yun" and Its Reasons
}

\author{
Wang Jiaojiao ${ }^{1,2, a}$ \\ ${ }^{1}$ School of Literature and Journalism, Sichuan University, Chengdu, China \\ ${ }^{2}$ School of Chinese Language and Literature, China West Normal University, Nanchong, China \\ amoyang841013@163.com
}

\begin{abstract}
The Chinese character "Yun" is a pictographic character in oracle bone inscriptions, whose original meaning is cloud, which refers to a physical phenomenon in nature. With the development and change of vocabulary, the meaning of

"Yun" is becoming more and more abundant.In addition to the traditional meaning summarized in dictionaries of past Dynasties, it also derives a new meaning, which is endowed with semantic features such as [+ Internet], [+ mass], [+ remote], [+ virtual] and [+ sharing].The evolution of the meaning of "Yun" is the result of the comprehensive effect of language itself, social era and cognitive psychology, which not only enlarges the rational meaning of "Yun", but also changes its color meaning and grammatical function.
\end{abstract}

Keywords : The Chinese character Yun, The evolution of word meaning, Result, Reasons

\section{“云”的词义演变及其原因分析}

\author{
王娇娇 $1,2, a$
}

${ }^{1}$ 四川大学文新学院, 成都, 四川, 中国

2 西华师范大学文学院, 南充, 四川, 中国

moyang841013@163.com

\section{摘要}

“云”在甲骨文中是一个象形字, 其本义表云彩, 指的是自然界中的一种物理现象。随着词汇的发展变化, “云” 的词义日渐丰富, 除了历代辞书中所归纳的传统词义以外, 还衍生出了全新的词义, 被赋子了 $[+$ 互联网 $]$ 、 $[+$ 海量性 $] 、[+$ 远程性 $] 、[+$ 虚拟性 $]$ 和 $[+$ 共享性 $]$ 等语义特征。“云” 的词义演变是语言自身、社会时代以及认知 心理等方面综合作用的结果，这一演变不仅使得 “云” 的理性义扩大，同时还使其色彩义和语法功能发生了改 变。

关链词: “云”，词义演变，结果，原因

\section{1. 前言:}

“云”字在甲骨文中就已出现，有テ烙むす、を等 字形。甲骨文中的 “云” 是一个象形字，上面的两横 表示天空, 下面的曲线表示飘浮在空中的气团。因此 “云” 的本义表示 “云雾” ，在这一本义的基础上, 经过演变发展逐渐衍生多种意义。下文笔者将根据辞 书中的释义以及文学作品中的用例来分析和归纳 “云” 的词义。

\section{2. “云” 的传统词义}

\section{1. “云” 在《说文解字》中的释义}

东汉许慎所著的《说文解字》是中国最早系统分 析汉字字形、考究字源的辞书，也是中国第一部按照 部首编排的字典。《说文解字》中说: “雲, 山川气 也。从雨, 云象雲回轉形。凡雲之屬皆从雲。云, 古 
文省雨。”段玉裁在《说文解字注》中解释道: “雲: 山川气也。天降時雨。山川出雲。从雨。云象回轉之 形。回上各本有雲字。今刪。古文衹作云。小管加雨 於上。遂爲半體會意、半體象形之字矣。云象回轉形、 此釋下古文雲爲象形也。王分切。十三部。凡雲之屬 皆从雲。云: 古文省雨。古文上無雨。非省也。二萾 上字。象自下回轉而上也。正月。昏姻孔云。傳曰。 云、旋也。此其引伸之義也。古多㷉云爲曰。如詩云 節詩曰是也。亦叞員爲云。如景員維河, 箋云員古文 作云、昏姻孔云本又作員、聊樂我員本亦作云、尚書 云來衛包以前作員來、小管妘字箩文作晋是。云員古 通用。皆殿借風雲字耳。自小管別為雲而二形迥判矣。 云: 亦古文雲。此冣初古文。象回轉之形者。其字引 而上行。書之所謂觸石而出、膚寸而合也。變之則爲 云。”由此可见, “云” 在《说文解字》中除了本义 (表示 “山川气”) 以外, 还有引申义 (表示 “周旋”) 和假借义（表示 “言说”）。

\section{2. “云” 在《康熙字典》中的释义}

《康熙字典》是张玉书等三十多位学者奉康熙圣 旨编撰的中国历史上第一部以字典命名的汉字辞书。 《康熙字典》中说: “【唐韻】【集韻】王分切【韻 會】【正韻】于分切, 茲音雲。【說文】山川氣也。 象回轉形。後人加雨作雲, 而以云爲云曰之云。【正 字通】與曰音別義同。凡經史, 曰通作云。又運也。

【管子・戒篇】天不動, 四時云下, 而萬物化。【註】 云: 運動貌。又狎昵往復也。【詩・小雅】昏姻孔云。 【朱傳】云: 旋也。【左傳 - 襄二十九年】晉不鄰矣, 其誰云之。【註】云: 猶旋。旋歸之也。又語助。【詩・小 雅】伊誰云憎。又陸佃曰: 云者, 有應之言也。【左 傳 - 襄二十六年】子朱曰: 朱也當御。三云: 叔向不 應。又云云: 衆語也。【史記・封禪書】文公獲若云 云于1㖦倉北坂。又【汲黯傳】武帝曰, 吾欲云云。

【註】猶言如此如此也。又云云: 山名。【前漢・郊 祀志】封大山禪云云。【註】云云：太山下小山。又 云爲。【易・繫辭】變化云爲。又姓。漢云敞。又與 芸同。【莊子・在宥篇】萬物云云。【註】盛貌。老 子作芸芸。又紛云：興作貌。【吕覽・園道篇】雲氣 西行云云然。【前漢 - 司馬相如傳】威武紛云。俗作 紜。又【韻補】叶于先切, 言也。【韓愈・剝啄行】 我謝再拜, 汝無復云。往追不及, 來可待焉。” 由此 可见， “云” 的词义进一步扩大，除了上文《说文解 字》中提到的义项, 还增加了运动; 语气助词; 像这 样; 山川之名; 姓氏; 盛多的样子; 相容云气缭绕的 样子等义项。

\section{3. “云” 在《现代汉语词典》（第 7版）中 的释义}

《现代汉语词典》是由中国社会科学院语言研究 所编纂的中国第一部规范性的语文词典。该词典以规 范性、科学性和实用性为主要特点, 在社会主义文化 建设中发挥了重要作用, 深受广大读者欢迎, 在海内
外享有很高声誉, 先后荣获国家图书奖、中国社会科 学院优秀科研成果奖和国家辞书奖。《现代汉语词典》 自 1978 年正式发行第 1 版, 至 2016 年 9 月先后共发 行了 7 版。《现代汉语词典》（第 7 版）中共有三个 云, 分别为云 ${ }^{1}$ 、云 ${ }^{2}$ 和云 ${ }^{3}$ 。其中云 ${ }^{1}$ 有三种词性, 做动词表示 “说” ; 做助词表强调; 做名词则指姓; 云 $^{2}$ ( 雲) 是名词, 表示 “在空中悬浮的由水滴、 冰晶凝聚形成的物体” ; 云 ${ }^{3}$ 为名词, 表示 “云南”。 由此可见, 《现代汉语词典》中的三个 “云” 是一组 同形同音词, 它们的读音相同、书写形式相同, 但意 义上却并无联系。

\section{4. “云” 的其他词义}

在查阅资料的过程中，笔者发现除了上文所提及 的义项, “云” 还具有以下含义: (1) 比喻轻柔如 云之物。如 “云衫玉带好威仪, 三洞真人入秦时。”

（唐・曹唐《小游仙诗》）；（2）造成损毁、受到 怀疑的事物，如 “疑云未消”; （3）借指高空，如 “灵皇皇兮既降, 芙远举兮云中。” (《楚辞・九歌・云 中君》）；（4）指围绕事物的某种假定介质, 如 “电 子云” ; (5) 指悬浮在空中的一种物质的细微质点, 如 “磨菇云” ; (6) 比喻高, 如 “黄帝得之, 以登 云天。”（《庄子・大宗师》）;（7）比喻疏远, 如 “云壤之别”;（8）比喻漂泊不定, 如 “云游四 海”；（9）表示 “有”，如 “其云益乎?”（《荀子・法 行》) ; (10）表示 “为、是”, 如 “虽云匹夫, 霸 王可也。” ( 《后汉书》) ……

由此可见, “云” 在本义的基础上逐渐衍生出了 多种意义。由于 “云” 的语义较为复杂, 为了方便人 们区分，在古代汉语中 “云” 字被拆分成 “雲”（后 又被简化成 “云” 字) 和 “云” 二字，前者一般作 名词和形容词, 后者一般作动词和语气词。

\section{3. “云” 的新兴词义}

在现代科技高度发展和新冠肺炎疫情防控的常 态化背景下，“云 X” 构式呈爆炸性增长趋势。2021 年 9 月 10 日笔者以 “云” 为关键词在人民网官方平 台上进行搜索，共检索到 118116 篇与 “云” 有关的 页面, 其中绝大多数的 “云 X” 构式已无法用 “云” 的传统释义来理解。由此可见, “云” 在现代社会中 已衍生变异出了新的词义, 这些新兴词义主要体现在 以下两方面:

\section{1. 指基于 “云计算” 进行信息处理的各种新 现象、新事物}

通过查阅相关资料，我们发现 “云 X” 构式最初 是以 “云理论” 和 “云计算” 形式出现于专业的学术 论文中; 直到 2006 年 8 月 9 日, Google 的首席执行 官埃里克・施密特（Eric Schmidt）在搜索引擎大会 (SES San Jose 2006) 上提出 “cloud computing” 
这一概念之后，“云计算”才逐渐走入我国普通民众 的视野, 出现了一大批基于云计算的新事物。比如“云 平台” 即云计算平台, 包括以数据存储为主的存储型 云平台, 以数据处理为主的计算型云平台以及计算和 数据存储处理兼顾的综合云计算平台; “云技术” 指 基于云计算商业模式应用的网络技术、信息技术、整 合技术、管理平台技术、应用技术等的总称; “云应 用”是云计算概念的子集，是云计算技术在应用层面 的体现; “云空调” 是指在制冷核心技术的基础上， 运用云计算技术对现有应用进行升级和管理的智能 化空调设备, 它拥有海量云端服务资源、远程控制等 众多应用优势, 并能实现软件更新和远程故障诊断;

“云课堂” 指的是在教育信息大数据备件下, 利用云 计算和云技术打造的现代化网络课堂……

\section{2. 指利用互联网技术线上远程实现的各种 行为或活动}

“云” 的本义指 “飘浮在空中的气团”，其 “相 互交织、变化无穷、难以触摸” 等特征与互联网有一 定的相似性, 因此在网络拓扑网中技术人员常用一朵 云的形状来表示互联网。后来随着互联网技术的发 展, “云” 逐渐成为了互联网的一种代称。各种基于 互联网技术远程实现的各种行为、活动或者现象都可 称之为 “云 X”。比如入选 “2020 年度十大网络用语” 的 “云监工” 是指通过网络 (观看直播等方式) 监督 某项工作的网友; “云拜年” 指春节期间利用互联网 远程拜年、相互祝福的行为; “云婚礼” 是指利用互 联网在直播平台上举行的不设喜宴、不待宾客的新兴 婚礼仪式; “云旅游” 在指在家中通过直播等方式游 览旅游景点的一种全新旅游模式; “云录制” 是指参 与节目的嘉宾在非演播厅通过视频设备连线交流进 行的节目录制; “云吸猫” 是指在快节奏生活下的年 轻人无法实现亲自养猫, 于是通过互联网观看视频、 图片或者与猫主人互动的方式来代替自己养猫的行 为…...

综上所述，各种依托现代科技的 “云生活” 业已 成为 “云时代” 下人们新兴生活方式。通过查阅相关 资料, 笔者发现 “云 X” 构式最初是以 “云理论” 和 “云计算” 形式出现于专业的学术论文中; 直到 2006 年 8 月 9 日, Google 的首席执行官埃里克 - 施密特 (Eric Schmidt) 在搜索引擎大会 (SES San Jose 2006）上提出 “cloud computing” 这一概念之后,

“云计算” 才逐渐走入我国普通民众的视野。尽管 Google 公司不是 “云计算”一词的首创者, 但其巨 大的影响力却在一定程度上推动了 “云 X” 构式在 IT 领域的流行。后来, 随着 “云计算” 技术在其他领域 的广泛运用, 再加之受到新冠疫情的巨大影响, “云 X” 构式逐渐从 IT 领域扩大到社会生活的各个方面。

\section{4. “云”词义演变的结果}

\section{1. 概念义的扩大}

词义扩大是词义发展演变的情况之一, 是指随着 社会时代的发展词语本身所指的对象范围扩大, 所应 用的范围也随之扩大的一种现象。从上文对 “云” 传 统词义以及新兴词义的梳理过程中可以看出, “云” 的概念义在不断地扩大，义项的数目也在不断增加。 “云” 不仅在本义 “悬浮在空中气团” 的基础上逐步 引申为 “盛多, 繁多”、“周旋，回旋”、“高”、 “疏远” 等义，而且还在现代科技的影响下，逐渐成 为了互联网的一种比喻说法。

\section{2. 色彩义的变化}

词汇意义由概念义和色彩义构成, 前者是指与概 念相联系的核心意义, 后者指附属于概念义的色彩 义。色彩义主要体现在感情色彩、语体色彩和形象色 彩三方面。就 “云” 的词义演变来看, 其感情色彩有 所变化。一开始, “云” 的本义是指 “山川气”, 是 自然界中的一种自然现象, 其感情色彩为中性。后来 随着科技的不断发展, 出现了少数带有贬义色彩的 “云 X”构式，比如 “云玩家” 和 “云球迷”。“云 玩家” 是指以间接的方式 (如网上攻略、图片、玩家 议论等）了解游戏而个人并没有真正接触、玩过该款 游戏或者对该游戏实际了解并不多的玩家。“云球迷” 是指不亲自观看球赛而是通过各种间接方式 (如新闻 报道、论坛评论等) 来了解比赛情况的球迷。这些云 玩家、云球迷由于没有亲身实践，因此对游戏以及球 赛的认识较为肤浅, 故这里的 “云” 带有一定程度的 贬义色彩。

\section{3. 语法功能的变化}

通过梳理 “云” 的词义, 可以看出 “云” 最初是 用作名词来发挥其语法功能, 本义指 “飘浮在空中的 气团”, 还可指 “像云一般柔软的物体”、“悬浮在 空中的某种物质”、“云南省的简称”、“姓氏” 等。 除了作名词以外, “云” 还有形容词、动词、语气词 等词性。随着传统古典文学的迅速发展, “云” 被文 人赋予了许多比喻和象征意义用作形容词, 如 “黄帝 得之, 以登云天” ( 《庄子・大宗师》) 中的 “云” 表 “高”之义; “齐子归止, 其从如云”（《诗经・齐 风・粉简》）中的 “云” 表 “盛多”之义。随着词汇 的变化发展, “云” 还被用作动词和助词。传世文献 中, “云” 作动词表言说义始见于 “我旧云刻子: 王 子弗出, 我乃颠阶。”（《尚书・商书・微子》）。 后来, 表言说义的 “云” 不断虚化为没有实在意义的 句末语气词, 如“当以训汝子孙, 使知前辈之风俗云。” (司马光《训俭示康》)。近年来涌现出来的各种 “云 X” 构式中的 “云” 具有较强的定位性和能产性, 是 一种新兴的类前缀。综上所述, “云” 的词性十分丰 富, 语法功能也在不断地发展变化中。 


\section{5. “云”词义演变的原因}

一般情况下，词义演变的原因主要有三方面：一 是内部因素即语言系统自身的原因; 二是外部因素即 社会时代的影响; 三是认知心理方面的因素。

\section{1. 内部因素}

语言的经济性原则要求语言在使用过程中既要 淋漓尽致地表达语义同时还要尽可能地做到少用语 言符号。因此在 “云” 词义的发展演变过程中, 拥有 名词、形容词、动词以及语气词等多种词性。此外, 在语言的发展变化过程中, 类推机制发挥着一定的作 用。这里的 “类推” 是指人们运用类比手法, 在原有 表达形式的基础上推演出新型表达形式的一种语言 机制。近年来出现的大量 “云 $X$ ” 构式就是人们在 “云 计算”、“云服务” 等词的基础上, 不断采用 “旧瓶 装新酒”的方式炮制出来的。

\section{2. 外部因素}

语言和社会的关系十分密切，语言反映了社会， 并随着社会的发展变化而不断变化发展。现代科技的 飞速发展以及新冠肺炎疫情防控的常态化使得人们 的生活方式发生了很大变化。这一社会背景使得人们 对在线教育、在线医疗以及在线娱乐等方面的需求不 断增加, 这些需求促使 “云 X” 构式逐渐从 IT 领域 逐渐扩大到社会生活的各大领域, 并逐渐生成了有别 于传统词义的新兴词义。

\section{3. 认知心理因素}

除了语言自身和社会因素的影响, 认知心理方面 的因素也是词义演变的重要原因之一。认知语言学认 为 “隐喻” 是人类重要的思维方式和认知方式。由于 自然界中的 “云” 和 “云 X” 构式中的 “云” 在物理 和心理层面均存在高度的相似性（详见表 1), 因此 人们便将利用这种相似性将始源域的图式结构映射 到目标域之上，使得 “云” 衍生出了新的词义。

表 1 自然界中的云与 “云 X” 中 “云” 的相似性

\begin{tabular}{|c|c|c|}
\hline 映射域 & 始源域 & 目标域 \\
\hline 联想项 & $\begin{array}{l}\text { 自然界中的 } \\
\text { “云” }\end{array}$ & $\begin{array}{l}\text { “云 } X \text { ” 中的 } \\
\text { “云” }\end{array}$ \\
\hline $\begin{array}{l}\text { 物理 } \\
\text { 相似性 }\end{array}$ & $\begin{array}{l}\text { 漫布天空 } \\
\text { 千姿百态 } \\
\text { 层层叠叠 } \\
\text { 相互交织 }\end{array}$ & $\begin{array}{l}++ \text { 海量性 }] \\
{[+ \text { 网络化 }]}\end{array}$ \\
\hline \multirow{2}{*}{$\begin{array}{l}\text { 心理 } \\
\text { 相似性 }\end{array}$} & $\begin{array}{l}\text { 飘忽不定 } \\
\text { 变幻无穷 }\end{array}$ & [+虚拟性] \\
\hline & $\begin{array}{l}\text { 世人共赏 } \\
\text { 难以触摸 }\end{array}$ & $\begin{array}{l}\text { [+共享性 }] \\
\text { [+远程性 }]\end{array}$ \\
\hline
\end{tabular}

众所周知, 社会性是人的本质属性。在社会生活 中，人们为了获取群体认同感，往往会有意无意地关 注和模仿强势言语社团所出现的各种新型表达, 这种 心理被称之为 “从众心理”。在这一心理的推动下, 一旦出现诸如 “云购物”、“云拜年” 等新颖独特的 表达形式，便会迅速被广大民众热捧和效仿。

\section{6. 结 论}

近年来所出现的 “云 X” 构式已无法用传统辞书 中对 “云” 的解释来理解，因此笔者在梳理 “云” 传 统词义的基础上, 分析了其在网络信息时代和疫情防 抗大背景下所衍生出来的新词义。“云” 的词义演变 不仅使其理性义扩大，同时还使其色彩义和语法功能 发生了极大改变。究其原因, “云” 的词义演变是语 言自身、社会时代以及认知心理等方面综合作用的结 果。“云 X” 构式的大量出现, 不仅满足了社会发展 变化的需要, 同时也大大丰富了汉语的构词方式和表 达手段。

\section{REFERENCES}

[1] Xu,Shen. (2013) Shuo Wen Jie Zi . Zhonghua Book Company, Beijing.

[2] Duan, Yucai. (1984) Annotation of Shuo wen Jie zi, Shanghai Ancient Books Publishing House, Shanghai.

[3] Zhang,Yushu.(1996) Kangxi Dictionary, Zhonghua Book Company, Shanghai.

[4] Chinese Academy of Social Sciences Institute of Linguistics Dictionary Editorial Office.(2017) Modern Chinese Dictionary (7th edition). Commercial Press, Beijing.

[5] Yang,W.Q., Yang,H. (2017) Derivative Mechanism and Cognitive Interpretation of Yun Neologisms, Global Chinese,4: 1-11.

[6] Zhang, L.P., Liu Z.P. (2020) Analysis of Yun X Construction, Journal of Western Anhui University, 36:119-124 